\title{
THE MEASUREMENT OF THE VELOCITY OF ABRASIVE PARTICLES AT THE SUCTION PART OF THE CUTTING HEAD
}

\author{
Josef Foldyna, Michal Zelenak, Jiri Klich, Petr Hlavacek, Libor Sitek, Zdenek Riha
}

Original scientific paper

To be able to optimize the design of the abrasive cutting head using the numerical simulation, it is necessary to gather as much information about processes occurring in the cutting head as possible. The development of numerical model of processes occurring in the abrasive water jet cutting head during the process of creation and forming of an abrasive water jet is currently in progress at the Institute of Geonics in Ostrava. The verification of the model requires, among other things, to determinate the behaviour of abrasive particles at the input of a cutting head. Therefore, the visualisation of abrasive particles at the input using various parameters of abrasive jet and its subsequent analysis were performed using the shadowgraphy (backlighting) technique. The results are presented in the paper.

Keywords: abrasive water jet; particle image shadowgraphy; velocity of abrasive particles

Mjerenje brzine abrazivnih čestica na usisnom dijelu rezne glave

Izvorni znanstveni članak

U svrhu optimiziranja konstrukcije abrazivne rezne glave primjenom numeričke simulacije, potrebno je prikupiti što više podataka o tome što se događa u reznoj glavi. U Institutu za geoniku u Ostravi upravo je u tijeku razvoj numeričkog modela postupaka koji se odvijaju u reznoj glavi abrazivnog vodenog mlaza tijekom stvaranja i formiranja abrazivnog vodenog mlaza. Za verifikaciju modela potrebno je, između ostalog, odrediti ponašanje abrazivnih čestica na ulazu u reznu glavu. Stoga se vizualizacija abrazivnih čestica na ulazu, pomoću različitih parametara abrazivnog mlaza i njegove analize, provela primjenom tehnike shadowgraphy (backlighting-pozadinsko osvjetljenje). Rezultati su prikazani u ovom radu.

Ključne riječi: abrazivni vodeni mlaz; brzina abrazivnih čestica; slika čestica dobivena pozadinskim osvjetljenjem - shadowgraphy

\section{Introduction}

The effects of high-speed abrasive water jets (jets with abrasive particles addition, AWJ) during the disintegration of materials are well known to the technical public. The principle of disintegration is based on the high-energy transmission to an extremely small area. The material destruction is then caused by complex physical processes during the jet impact, such as erosion, shearing, failure under rapidly changing localized stress fields, or micromachining effects, all depending on the specific properties of the material being disintegrated $[1 \div 4]$. No thermal influences on the cutting surface as well as the universality are important advantages of abrasive water jets. With a single water jet based system, several machining operations can be performed on a wide range of materials and geomaterials. Abrasive water can cut, drill, turn, mill, etc. difficult-to-machine materials such as composites, structural ceramics, high-strength alloys, glass, rocks, etc.

The AWJ cutting head represents the key component in the process of the generation of an abrasive water jet. As can be seen in Fig.1, the high-pressure water flows through the water jet nozzle with small orifice diameter $d_{0}$ and it forms a high-speed water jet having the speed within the range from 300 to $850 \mathrm{~m} / \mathrm{s}$, depending on the water pressure. Abrasive solid particles are sucked by the air flow into the mixing chamber by the water jet pumping effect $[5 \div 8]$. Mixing of abrasive particles with the air and high speed water jet is done inside the mixing chamber and the mixture is further guided and accelerated in the focusing tube. Due to the recombination of speeds of water and air-abrasive flows, a high-speed abrasive water jet is formed.

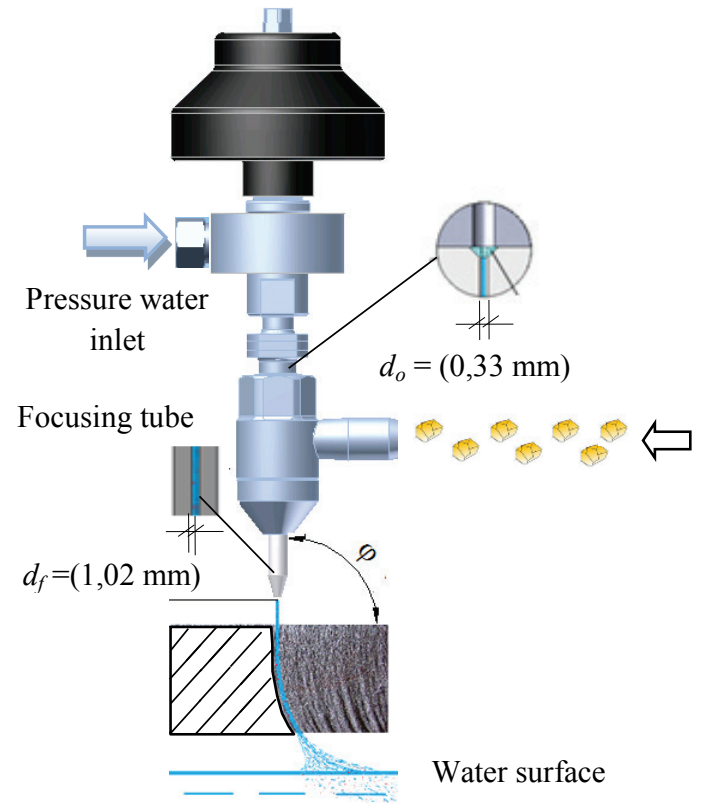

Figure 1 Schematic drawing of AWJ cutting head

The internal geometrical configuration and arrangement of an AWJ cutting head influences the quality and effectiveness of an abrasive water jet. Regardless the fact that AWJ cutting heads have been commonly used for more than three decades, there is still certain lack of knowledge concerning the processes occurring in an AWJ cutting head during the process of creation and forming of an abrasive water jet. Therefore, a numerical model of the AWJ cutting head has been recently developed at the Institute of Geonicsin Ostrava using the ANSYS CFD software to simulate numerically the process of generating and forming of an abrasive 
water jet. The verification of the model requires, among others, to determinate the behaviour of abrasive particles at the input in the AWJ cutting head. Therefore, the visualisation of abrasive particles at the input to the AWJ cutting head using various processing parameters and its subsequent analysis oriented towards the determination of abrasive particle velocity were performed using the shadowgraphy (backlighting) technique. The experiment results are presented in the paper below.

\section{Use of the shadowgraphy technique for the flow visualisation of particles at the suction part}

The shadowgraphy technique is one of popular measurement methods used for the flow visualisation. It is commonly used for the study of motion of particles, liquids or gases [9] in many technical applications. The measurement results provide information about size distribution, shape and velocity of particles. This technique is based on the principle of the high resolution imaging with the pulsed backlight illumination. Typical shadowgraph system is similar to the 2D planar PIV system and it consists of one CCD double frame camera with macrolens (or microscope) and a double pulsed laser. The light sheet used for measurement in the PIV applications is replaced by special optical diffusor. The camera lens images the target on the sensor array of a digital camera. The particles seeded in the flow are illuminated by the optical diffusor and they create shadow points on the contrast background of a recorded image. The first image of the double frame series acquired by the CCD camera is taken at time $t$ and the second image after a short time delay $\mathrm{d} t$. Each frame is taken under illumination by the double pulsed laser. The camera and laser illumination are synchronized by a programmable timing unit. The double frame mode of the camera allows defining of the particle movement, which is necessary for subsequent particle detection and analysis. After the acquisition of double frame series, the images are subdivided into small areas called interrogation windows.

$$
\begin{aligned}
& R_{f g}(x, y)=\iint_{-\infty}^{\infty} f(\xi+x, \zeta+y) g(\xi, \zeta) \mathrm{d} \xi \mathrm{d} \zeta, \\
& R_{f g}(m, n)=\sum_{k=-\infty}^{\infty} \sum_{l=-\infty}^{\infty} f(k+m, l+n) g(k, l) .
\end{aligned}
$$

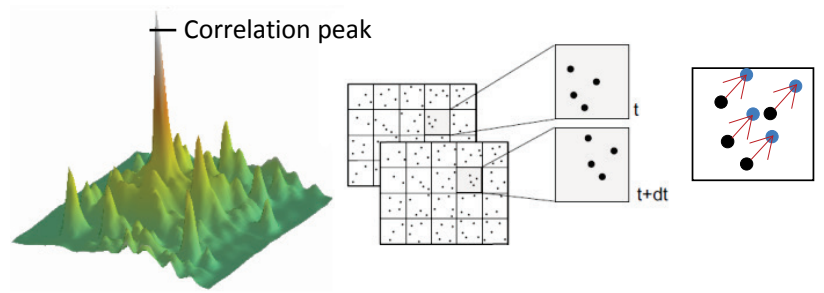

Figure 2 Use of cross correlation function for particle detection and determination of local particle movement in two interrogation areas

The interrogation windows are cross-correlated to each other, pixel by pixel (see Fig.2) [10, 11, 12], using the following cross correlation function Eq. (1): The Eq. (2) describes the cross correlation function for digital images. The type of algorithm to be used for analysis is determined by the particle density. The PTV "Particle tracking velocimetry" method suitable for study of individual particles is required in case of low particle density. Before the velocity is calculated, the sizing algorithm is applied to each frame of source images. To determine the size of particles, a thresholding two-step segmentation algorithm is applied. The first segmentation allows the locating of particles in so-called bounding boxes; secondly the same segments are analysed separately in order to determine the size, shape and position. The use of segmentation algorithm will be described in the next chapter.

\section{Experimental procedure}

The experimental assembly used for the visualisation of abrasive particles and the measurement of their velocity at the input of the AWJ cutting head consisted of a high-pressure pump (delivering up to $7,8 \mathrm{l} / \mathrm{min}$ at the maximum operating pressure of $415 \mathrm{MPa}$ ), an AWJ cutting head, a water catching tank and a system for the shadowgraphy measurement. A schematic drawing of the experimental setup can be seen in Fig. 3. The AWJ cutting head (equipped with a diamond nozzle orifice with diameter $d_{0}=0,33 \mathrm{~mm}$ and a focusing tube with diameter $d_{f}=1,02 \mathrm{~mm}$ ) was installed on the arm of the ABB IRB 6640 robot placed over the catching tank. The CCD camera with a macro lens was positioned perpendicularly to the input of the AWJ cutting head and the laser equipped with an optical diffusor was placed behind the input of the AWJ cutting head to create the backlight illumination in the field of view of the camera. The camera was operating at the double frame mode with the maximum recording rate of $15 \mathrm{~Hz}$ and the laser illumination was synchronized with it. The maximum output power of the laser was $2 \times 180 \mathrm{~mJ}$ for each laser pulse and the time delay between $1^{\text {st }}$ and $2^{\text {nd }}$ laser pulse was changed from 13 to $20 \mu \mathrm{s}$, depending on operating parameters of the AWJ.

The time delay between the first and second frame (as well as the laser illumination) was determined by the required displacement of particles with respect to the displayed area and the magnification of the field of view. The measurement area of the input of the AWJ cutting head was defined by the focal plane with the depth of imaging area. A schematic picture of the position of measurement area towards the input of the AWJ cutting head and the detail of a field of view (FOV) can be seen in Fig. 4. In the measurement area, the section of a plastic tube which is commonly used for the delivery of abrasive particles to the AWJ cutting head was replaced by a glass tube. The inner diameter of the glass tube was $18 \mathrm{~mm}$ in order to improve optical conditions and resolution of the area of interest (the influence of the enlarged diameter of the glass tube in relation to the diameter of the standard tube was neglected in the experiment). The FOV size was set to $1600 \times 500$ pixels, the scale factor was 0,017 $\mathrm{mm} /$ pixel. All information regarding the recording setup is summarized in Tab. 1 . 

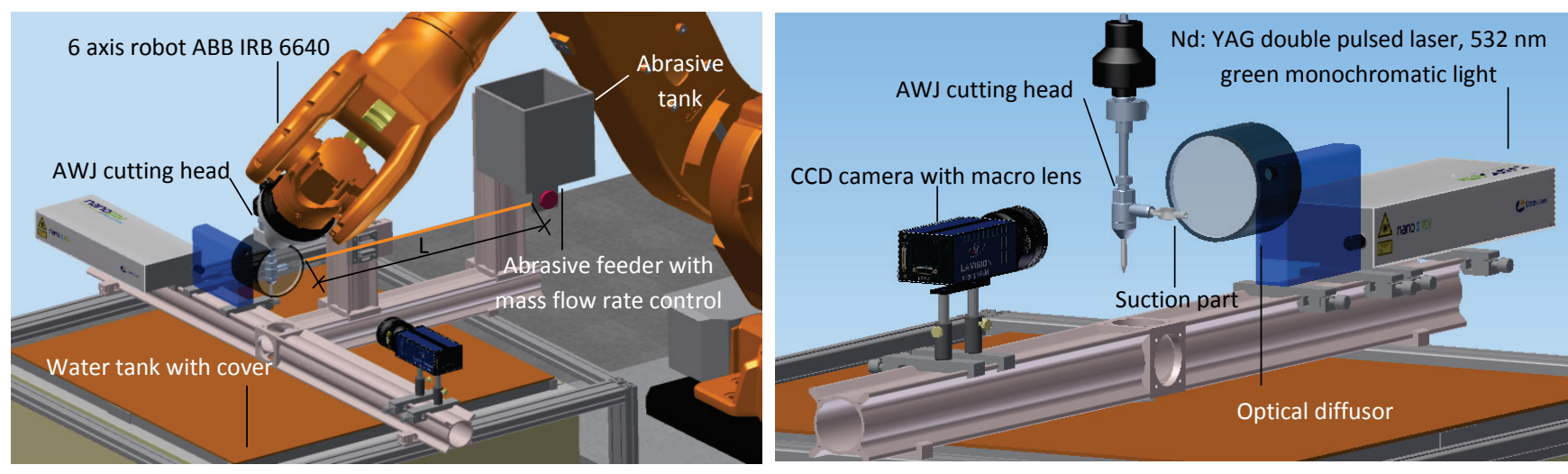

Figure 3 Schematic drawing of experimental plan

Table 1 Recording setup of camera
\begin{tabular}{|l|c|}
\hline \multicolumn{1}{|c|}{ Parameter } & Value \\
\hline Camera resolution & $1600 \times 1200$ pixel \\
\hline Image size & $28,68 \times 21,51 \mathrm{~mm}$ \\
\hline FOV size & $1600 \times 500$ pixel \\
\hline Image size & $28,68 \times 8,95 \mathrm{~mm}$ \\
\hline Scale factor & $0,017 \mathrm{~mm} /$ pixel \\
\hline Recording mode & double frame \\
\hline Recording rate & $15 \mathrm{~Hz}$ \\
\hline Number of experimental images & 100 \\
\hline Number of reference images & 5 \\
\hline $\begin{array}{l}\text { Time delay between } 1^{\text {st }} \text { and } 2^{\text {nd }} \\
\text { illumination of laser }\end{array}$ & $13 \div 20 \mu \mathrm{s}$ \\
\hline Max output power of laser & $2 \times 180 \mathrm{~mJ}$ \\
\hline
\end{tabular}

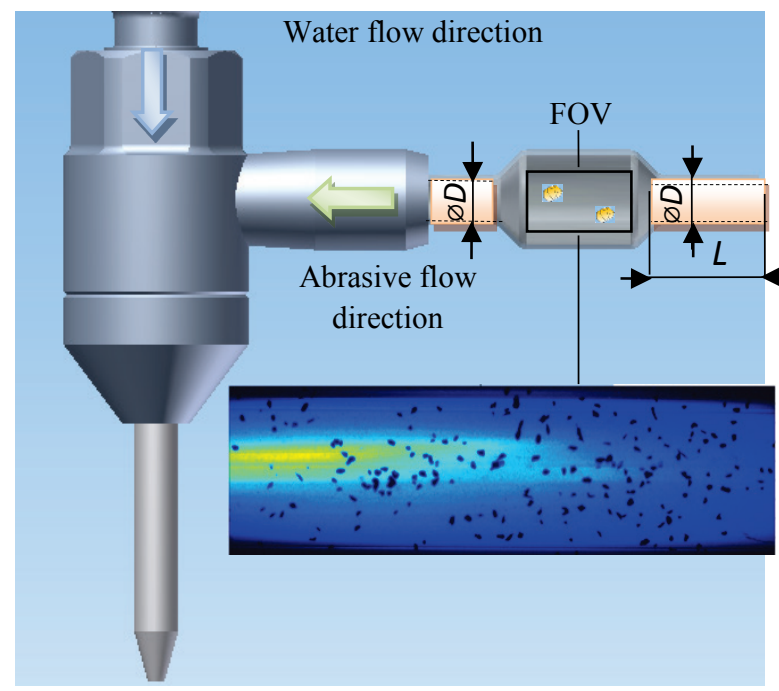

Figure 4 Detail of visualization of abrasive particles at the input of cutting head

Five reference images were taken prior to every measurement; influences of the cyclic pulse to pulse variations from the laser illumination in the reference image are reduced, when a series of images is taken [10]. This procedure is necessary after acquisition of the time series of experimental images for their subsequent averaging and inverting to shadow images. An example of a reference image after its averaging is shown in Fig. 5a). As can be seen, it was not possible to obtain an image with uniform count intensity due to the use of an ordinary cylindrical glass tube in front of the optical diffusor. An experimental image with abrasive particles is presented in Fig. 5b). The particles are displayed as dark points in contrast with the image background. An example of an inverted image with low background intensity and relatively high intensity of the light across the displayed particle is shown in detail in Fig. 5c).

A thresholding two-step segmentation algorithm was applied for the particle detection. In the first step of segmentation, abrasive particles were detected in bounding boxes and consequently, the segments were analysed separately according to their size, shape and position. After the segmentation, all detected particles can be analysed individually [10]. An example of a velocity image of analysed particles with detailed particle information can be seen in Fig. 6. 


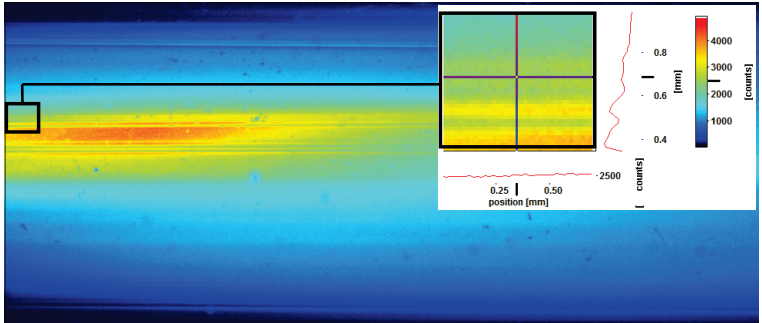

a)

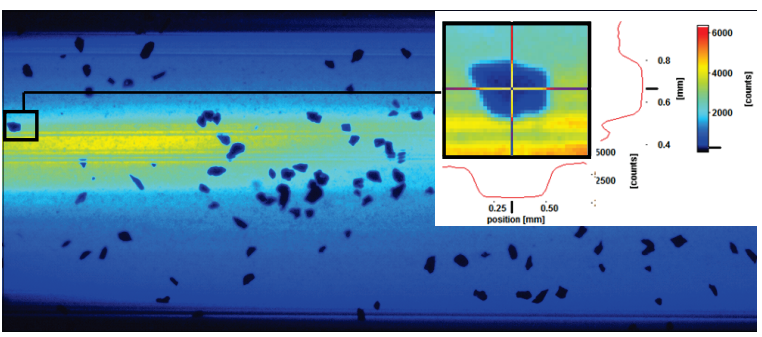

b)

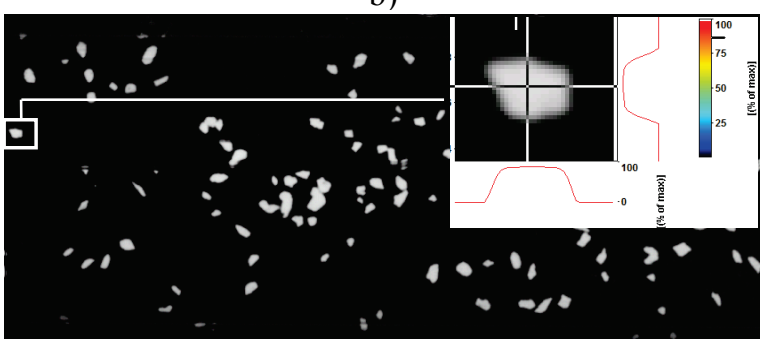

c)

Figure 5a) Reference image after averaging five images into one, b) experimental image with abrasive particles, c) inverted image after subtracting reference and experimental image

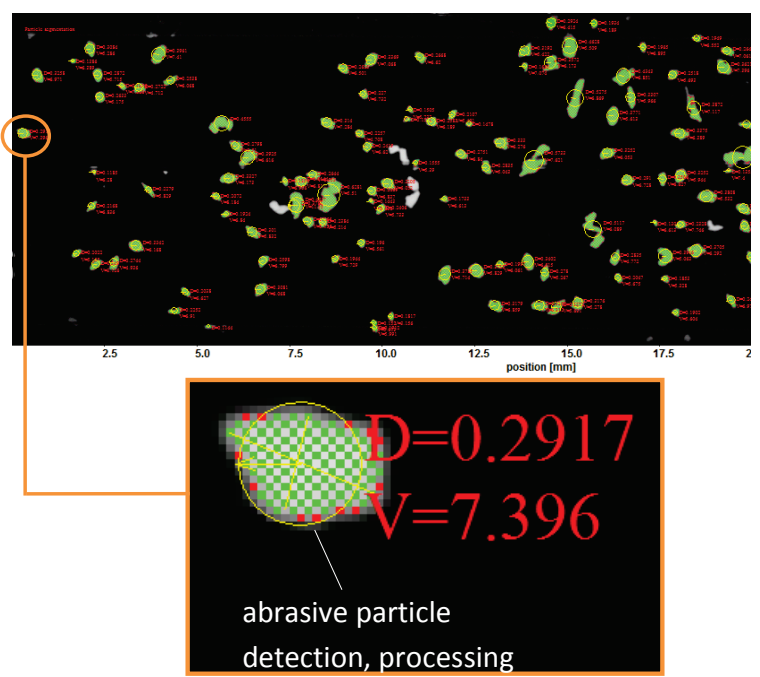

Figure 6 Detection and processing of abrasive particles

\section{Experimental results and discussion}

Experimental results of the measurements of the abrasive particle velocity in the suction part of the AWJ cutting head are presented in the form of histogram graphs with normal distribution fits (Gaussian). The influence of the water pressure and of the abrasive flow rate on the abrasive particle velocity is illustrated in Fig. 7. The graphs indicate that increase in water pressure results in a slight increase in abrasive particle velocities in the suction part of the abrasive cutting head. For example, the average particle velocity at the abrasive mass flow rate of $300 \mathrm{~g} / \mathrm{min}$ increases from about $5,9 \mathrm{~m} / \mathrm{s}$ at the working pressure of $210 \mathrm{MPa}$ to approximately $6,7 \mathrm{~m} / \mathrm{s}$ at the working pressure of $400 \mathrm{MPa}$. A similar increase in abrasive particles velocities with increase in working pressure can be also observed in case of other abrasive mass flow rates which were tested. This can be caused by an increased air flow rate occurring at higher pressures resulting in higher air velocity and consequent higher velocity of abrasive particles.

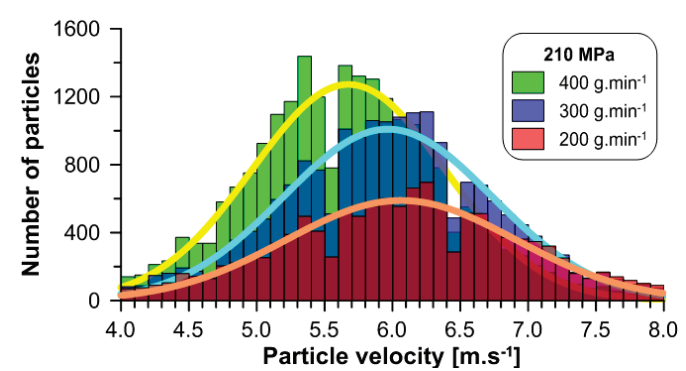

a)

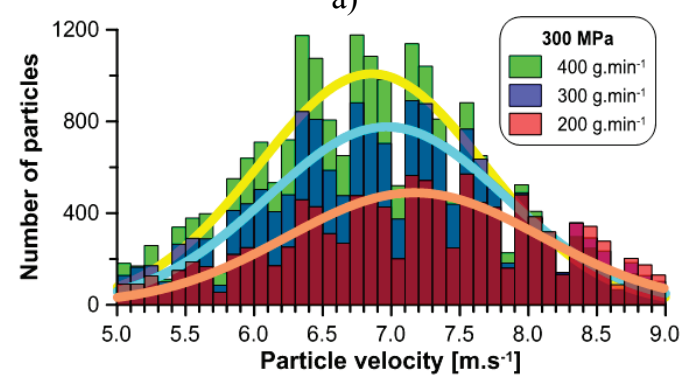

b)

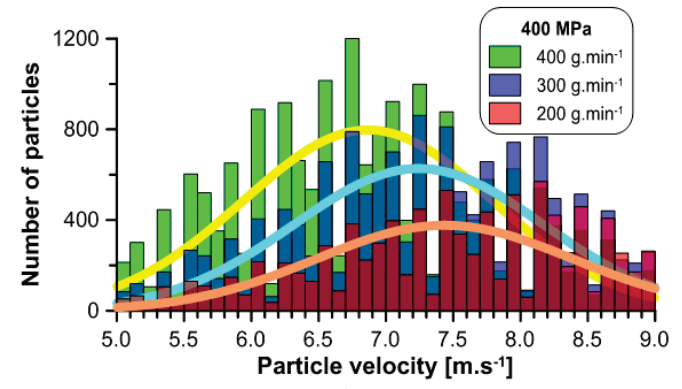

c)

Figure 7 Influence of water pressure and abrasive flow rate on abrasive particle velocity for plastic tube $\varnothing D=6,4 \mathrm{~mm}, L=0,53 \mathrm{~m}$; a) $p=210 \mathrm{MPa}$; b) $p=300 \mathrm{MPa}, \mathrm{c}) p=400 \mathrm{MPa}$

As can also be seen in Fig. 7, the increase of the abrasive mass flow rate has an adverse effect on the abrasive particle velocity - a slight decrease of the particle velocity can be observed at all tested working pressures when the abrasive mass flow rate increases. This is probably due to the fact that a larger number of particles have to be accelerated by the same air flow at higher abrasive mass flow rate. The influence of the inner diameter of the plastic tube used for the delivery of abrasive particles to the AWJ cutting head on the abrasive particle velocity is shown in Fig. 8. According to the graph it is obvious that the abrasive particle velocity in the suction part of the AWJ cutting head is strongly influenced by the plastic tube diameter. This is due to the fact that the underpressure in a tube with smaller inner diameter is higher under identical operating conditions. As a result, the air velocity in the plastic tube of smaller inner diameter is correspondingly higher and, therefore, the velocity of abrasive particles is also higher. 


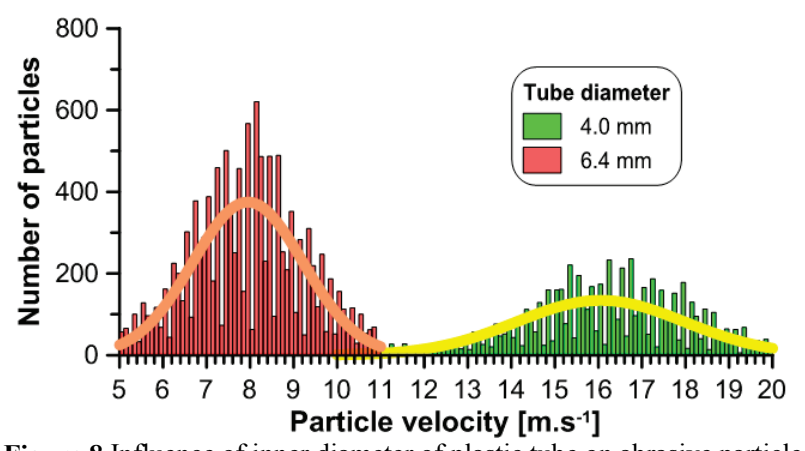

Figure 8 Influence of inner diameter of plastic tube on abrasive particle velocity (other parameters were maintained constant: $p=400 \mathrm{MPa}$, $\left.m_{\mathrm{a}}=200 \mathrm{~g} / \mathrm{min}, L=1,5 \mathrm{~m}\right)$

Fig. 9 illustrates the influence of the length of the plastic tube for the delivery of abrasive particles to the AWJ cutting head on the abrasive particle velocity. The results indicate that only marginal increase of particle velocities occurs when the plastic tube is longer.

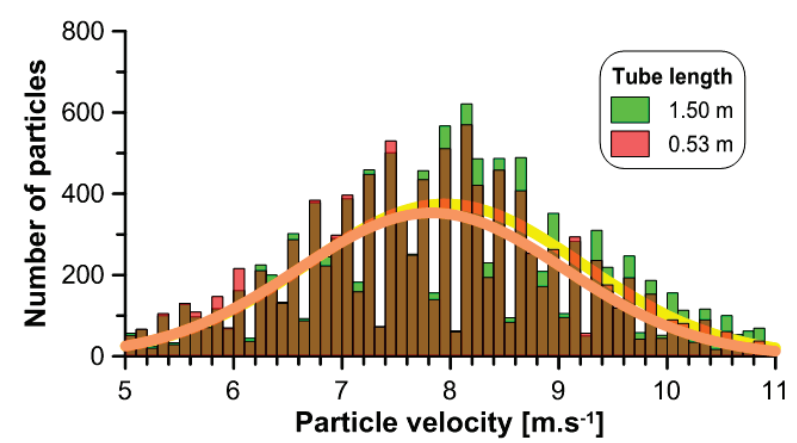

Figure 9 Influence of length of plastic tube on abrasive particle velocity (other parameters were maintained constant: $p=400 \mathrm{MPa}, m_{\mathrm{a}}=200 \mathrm{~g} / \mathrm{min}$, $\varnothing D=6,4 \mathrm{~mm})$

\section{Conclusions}

The experimental work oriented at the determination of the abrasive particle velocity at the input of the AWJ cutting heads leads to the following conclusions:

- increase in the working pressure results in a slight increase in abrasive particle velocities;

- increase in the abrasive mass flow rate results in a small decrease in abrasive particle velocities;

- decrease in the inner diameter of the plastic tube for the delivery of abrasive particles to the AWJ cutting head results in significant increase in abrasive particle velocities;

- longer plastic tube for the delivery of abrasive particles to the AWJ cutting head has only a minor influence on velocities of abrasive particles.

The results will be used for the verification of a numerical model of the AWJ cutting head developed to simulate numerically the process of generation and formation of an abrasive water jet. However, further laboratory experiments for the model verification are required (such as the measurement of pressures inside the AWJ cutting head and the measurement of abrasive particle velocities in the abrasive water jet). After the verification, the numerical model will be used to optimize the AWJ cutting head design to increase the cutting performance of the abrasive water jet.

\section{Acknowledgements}

The article was written in connection with the project of Institute of clean technologies for mining and utilization of raw materials for energy use, reg.no. CZ.1.05/2.1.00/03.03.0082, which is supported by the "Research and Development for Innovations" Operational Programme financed through the European Union Structural Funds and through the State budget of the Czech Republic. The presented work was also supported by the Ministry of Industry and Trade of the Czech Republic, project FR-TI3/733, and by the Academy of Sciences of the Czech Republic, project RVO 68145535. Authors are very grateful for the support.

\section{References}

[1] Kim, T. J.; Labus, T. J. Influence of basic jet parameters and physics of abrasive water jet cutting. // Fluid jet technology: Fundamentals and applications / Proceedings of the WJTA / St. Louis, 1995. pp. 3.1-3.45.

[2] Marusic, V.; Baralic, J.; Nedic, B.; Rosandic, Z. Effect of machining parameters on jet lagging in abrasive water jet cutting. // Tehnicki vjesnik-Technical Gazette. 20, 4(2013), pp. 677-682.

[3] Gov, K.; Eyercioglu, O.; Cakir, M. V. Hardness Effects on Abrasive Flow Machining. // Strojniški vestnik - Journal of Mechanical Engineering. 59, 10(2013), pp. 626-631. DOl: 10.5545/sv-jme.2013.1129

[4] Hashish, M.; Abrasive jets. // Fluid jet technology: Fundamentals and applications / Proceedings of the WJTA / St. Louis, 1995, pp. 4.1-4.52.

[5] Liu, H.; Wang, J.; Kelson, N.; Brown, R.J. A study of abrasive water jet characteristics by CFD simulations. // Journal of Material Processing Technology. 153, 1(2004), pp. 488-493. DOI: 10.1016/j.jmatprotec.2004.04.037

[6] Osman, A. H.; Mabrouki, T.; Théry, B.; Buisine, D. Experimental analysis of high-speed air-water flow in an abrasive water jet mixing tube. // Flow measurement and Instrumentations. $15, \quad(2004), \quad$ pp. 37-48. DOl: 10.1016/j.flowmeasinst.2003.08.001

[7] Hloch, S.; Ruggiero, A. Online monitoring and analysis of hydro abrasive cutting by vibration. // Advances in Mechanical Engineering. (2013), pp. 1-10. DOI: 10.1504/IJSURFSE.2013.053699

[8] Hreha, P.; Hloch, S. Potential use of vibration for metrology and detection of surface topography created by abrasive waterjet. // International Journal of Surface Science and Engineering. 7, (2013), pp. 135-151.

[9] Garcia, R.; Pita Castrejon, J. R.; Martin, G. D.; Hutchings, I. M. The shadowgraph imaging technique and its modern application to fluid jets and drops. // Revistamexicana de fiscia. 57, (2011), pp. 266-275.

[10] Particle Master Shadow. // Lavision. Manual number 1003014, (2012).

[11] Raffel, M.; Willert, C. E.; Kompenhans, J. Particle image velocimetry: A practical guide. Springer Verlag, Berlin, 1998. DOI: 10.1007/978-3-662-03637-2

[12] Adrian, R. J.; Westerweel, J. Particle Image Velocimetry. Cambridge University Press, Cambridge, 2011.

\section{Authors' addresses}

Josef Foldyna

Institute of Geonics of the ASCR, Institute of Clean Technologies for Mining and Utilization of Raw Materials for Energy Use, Studentska 1768/9 70800 Ostrava-Poruba, Czech Republic josef.foldyna@ugn.cas.cz 


\section{Michal Zeleňák}

Institute of Geonics of the ASCR, Institute of Clean Technologies for Mining and Utilization of Raw Materials for Energy Use, Studentska 1768/9 70800 Ostrava-Poruba, Czech Republic michal.zelenak@ugn.cas.cz

\section{Jiri Klich}

Institute of Geonics of the ASCR, Institute of Clean Technologies for Mining and Utilization of Raw Materials for Energy Use, Studentska 1768/9 70800 Ostrava-Poruba, Czech Republic jiri.klich@ugn.cas.cz

\section{Petr Hlavacek}

Institute of Geonics of the ASCR, Institute of Clean Technologies for Mining and Utilization of Raw Materials for Energy Use, Studentska 1768/9 70800 Ostrava-Poruba, Czech Republic petr.hlavacek@ugn.cas.cz

\section{Libor Sitek}

Institute of Geonics of the ASCR, Institute of Clean Technologies for Mining and Utilization of Raw Materials for Energy Use, Studentska 1768/9 70800 Ostrava-Poruba, Czech Republic libor.sitek@ugn.cas.cz

\section{Zdeněk Říha}

Institute of Geonics of the ASCR, Institute of Clean Technologies for Mining and Utilization of Raw Materials for Energy Use,

Drobneho 2860200 Brno, Czech Republic

zdenek.riha@ugn.cas.cz 